\title{
Hemodynamic changes associated with laparoscopic cholecystectomy: Effect of oral clonidine premedication.
}

\author{
Dr Dhiraj Bhandari ${ }^{1}$, Dr Sucheta Tidke ${ }^{2}$, Dr Vijay Sharma ${ }^{3}$, Dr Himanshu \\ Dongre $^{4}$, Dr Dipika Garg ${ }^{5}$, Dr Pradeep Dhande ${ }^{6}$. \\ 1, 3: Assistant Professor, 2: Professor, 6: Professor and Head, all at department of Anaesthesiology, MGIMS, \\ Sewagram, Wardha, India. 4: Consultant Anaesthesiologist, Sancheti Hospital, Pune. 5: Assistant Professor, \\ ENT and Head Neck Surgery, MGIMS, Sewagram, Wardha, India.Corresponding Author: Dr Dhiraj Bhandari. \\ Address: Department of Anaesthesiology, MGIMS, Sewagram, Wardha, Maharashtra, India.
}

\begin{abstract}
Pneumoperitoneum required for laparoscopy results in pathophysiologic changes, especially in the cardiovascular system. Clonidine, an alpha 2 agonist has been shown to be effective in reducing perioperative hemodynamic instability. The aim of our study was to assess the hemodynamic changes during laparoscopic cholecystectomy and to find the effect of oral clonidine premedication in prevention of these hemodynamic responses.100 adult ASA I and II patients scheduled for elective laparoscopic cholecystectomy were selected for this prospective randomized double blinded comparative study. They were randomly allocated to one of the two groups to receive either oral clonidine 150 micrograms (Group C) or ranitidine $150 \mathrm{mg}$ (group B) 90 minutes prior to induction of anaesthesia. When vital parameters were compared significant rise in heart rate, systolic, diastolic and mean blood pressure was noted in group B following pneumoperitoneum, where as in group $\mathrm{C}$ patients the rise if present was not more than $10 \%$ of baseline. Nitroglycerine drip was required in $28 \%$ of patients in group B to control intraoperative hypertension. Incidence of postoperative adverse events like nausea-vomiting, shivering and pain was also lower in patients who received clonidine premedication, though they appeared to be more sedated.In conclusion, clonidine premedication provides perioperative hemodynamic stability in ASA I and II patients undergoing laparoscopic cholecystectomy, and hence can be recommended as a routine premedication for laparoscopic procedure.
\end{abstract}

Keywords-Laparoscopic cholecystectomy, Pneumoperitoneum, Hemodynamic response, Clonidine premedication.

\section{INTRODUCTION}

Because of its cosmetic scar, less postoperative pain, decreased hospital stay and obviously less mortality, it has become the gold standard for treatment of gall bladder diseases ${ }^{1}$. Laparoscopic cholecystectomy is one of the most commonly undertaken procedures in general surgery, with overall complication rate being less than $1.5 \%$, and the mortality being less than $0.1 \%{ }^{2}$. However pneumoperitoneum (PNP) required for this procedure affects several systems leading to alterations in cardiovascular, respiratory, stress response and acid base physiology.

The nature of changes in cardiovascular system associated with pneumoperitoneum includes an increase in mean arterial pressure, decrease in cardiac output and increase in systemic vascular resistance which can lead to altered tissue perfusion. These changes though better tolerated in ASA I and II patients can be detrimental in elderly and ASA III patients particularly with compromised cardiovascular system physiology. Various surgical methods like change in nature of insufflating gas ${ }^{3}$ use of low intra-abdominal pressure ${ }^{4,5}$, use of abdominal wall lift methods ${ }^{6}$, have been tried to decrease the hemodynamic alterations seen with pneumoperitoneum, but all with practical limitations. Various anesthetic interventions like use of epidural, segmental spinal ${ }^{7}$, combined epidural and general anaesthesia $^{8}$, use of various pharmacologic interventions like nitroglycerine ${ }^{9}$, esmolol ${ }^{10}$, magnesium sulphate ${ }^{11}$ have been used with varying success and practical limitations.

Aho et $\mathrm{al}^{12}$ used alpha 2 adrenergic receptor agonist for prevention of hemodynamic responses associated with laparoscopic surgery. They found that dexmedetomidine effectively reduces the maximum heart rate response after intubation and pneumoperitoneum. Clonidine modulates the hemodynamic changes induced by pneumoperitoneum by inhibiting the release of catecholamines and vasopressin ${ }^{13}$.

With this background the present study was designed to investigate the hemodynamic changes associated with laparoscopic cholecystectomy and the effect of oral clonidine premedication in prevention of such changes. 


\section{METHODS}

This randomized double blind prospective study was carried out in 100 ASA I and II patients scheduled for elective laparoscopic cholecystectomy the department of anesthesiology, MGIMS, sewagram Maharashtra after the approval of local institutional ethical committee. Written informed consent was obtained from the patients. Patients with history of ischemic heart disease, aortic stenosis, atrio ventricular blocks, past history of heart failure and patients concomitantly taking clonidine, methyl dopa, beta blockers and calcium channel blockers were excluded from the study.

Preanaesthetic checkup and routine investigations like complete blood count, serum creatinine and ECG were done. Patients were kept nil by mouth for 6 hours. All patients received $5 \mathrm{mg}$ tab diazepam orally on the night before surgery. They were randomly assigned to one of the two groups to receive either clonidine 150 micrograms (Group C) or ranitidine 150mg (Group B) orally 90 minutes before induction of anaesthesia. The observer was totally blind about the groups or medications received by the patients. Group sizes of 50 were determined by power analysis based on standard deviation data from previously published reports.(change language)

After coming in operation theatre, intravenous line was secured and. Baseline parameters such as heart rate, systemic arterial pressure and peripheral oxygen saturation were noted down, radial artery was cannulated to obtain invasive blood pressure reading. Level of sedation (sedation score) was assessed by sedation scale.

After intravenous cannulation, glycopyrrolate $0.2 \mathrm{mg}$, was administered intravenously. Patients were induced with sleep dose of Propofol. Endotracheal intubation was facilitated by succinylcholine $1.5 \mathrm{mg} . \mathrm{kg}-1$ of body weight. Anaesthesia was maintained with $50 \%$ oxygen in nitrous oxide, $1 \%$ isoflurane and vecuronium bromide $0.1 \mathrm{mg} . \mathrm{kg}-1$. Preoperative analgesia was provided by fentanyl citrate $1.5 \mu \mathrm{g} . \mathrm{kg}-1$ body weights. The intermittent positive pressure (IPPV) ventilation was continued.

Pneumoperitoneum was created by insufflation of carbon dioxide and operation table was tilted about $15^{\circ}$ reverse trendelenberg position. Intra abdominal pressure (IAP) was not allowed to exceed $15 \mathrm{~mm} \mathrm{Hg}$ throughout the surgical procedure. . Adjustments in tidal volume and respiratory rate were done so as to keep the end tidal carbon dioxide $\left(\mathrm{EtCO}_{2}\right)$ concentrations between $30-40 \mathrm{mmHg}$ throughout the procedure.

Throughout the procedure concentration of isoflurane was kept constant and any rise in mean arterial pressure more than $20 \%$ from the baseline was treated with nitroglycerine drip.

Systemic arterial pressure including the systolic, diastolic and mean arterial pressure, heart rate, $\mathrm{SpO} 2, \mathrm{EtCO} 2$ and electrocardiography (ECG) with ST segment analysis were recorded at the following points of time: 1 . Baseline prior to premedication 2. Prior to induction 3. Three minutes after endotracheal intubation 4.before pneumoperitoneum (5. fifteen minutes after pneumoperitoneum 6 . thirty minutes after pneumoperitoneum 7 . ten minutes after release of $\mathrm{CO} 2$ and 8 . ten minutes after extubation.

At the end of surgery residual neuromuscular block was reversed by neostigmine and glycopyrrolate intravenously. Trachea was extubated and patients were transferred to recovery room. In the postanaesthesia care unit (PACU) they were monitored for any evidence of complications or adverse events. Degree of sedation and intensity of pain were also assessed by using observer assessment of analgesia and sedation scale (OASS).

The results obtained in the study are presented in tabulated manner. Statistical analysis was done by students' $\mathrm{t}$ ' test. Chi square test was performed for nonparametric values and corresponding $P$ was computed. $P$ value $<0.05$ was considered statistically significant.

\section{RESULTS}

Data is presented as mean, unless otherwise stated. Figures in bracket indicate standard deviation. Demographic parameters were comparable in both the groups. (table 2).

TABLE 2: DEMOGRAPHIC PROFILE OF BOTH THE GROUPS: MEAN (SD)

\begin{tabular}{|l|l|l|l|l|}
\hline $\begin{array}{l}\text { DEMOGRAPHIC } \\
\text { PROFILE }\end{array}$ & GROUP B & GROUP C & P VALUE & SIGNIFICANCE \\
\hline SEX (F:M) & $34: 16$ & $32: 18$ & 0.673 & NS \\
\hline AGE (YEARS) & $37.58(10.82)$ & $38.86(10.36)$ & 0.5473 & NS \\
\hline WEIGHT (KG) & $54.64(7.64)$ & $52.20(7.43)$ & 0.1082 & NS \\
\hline ASA CLASS(I:II) & $35: 15$ & $37: 13$ & 0.656 & NS \\
\hline MEAN EtCO2 & $31.26(2.92)$ & $32.02(3.58)$ & 0.2271 & NS \\
\hline
\end{tabular}

NS: Not significant

The mean intra-abdominal pressure was maintained less than $14 \mathrm{mmHg}$ in both the groups. 


\section{GRAPH 1: TABLE SHOWING HEART RATE IN BOTH THE GROUPS}

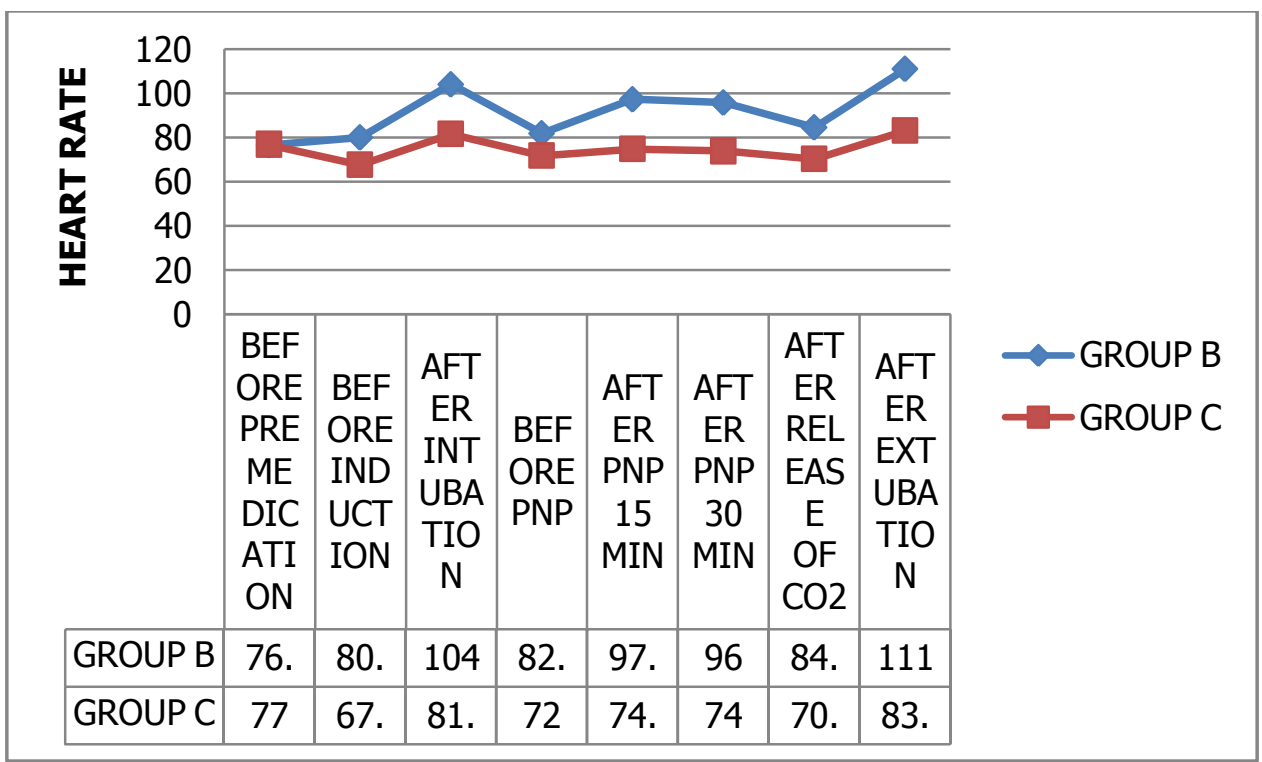

Mean heart rate varied from 76.8(10.99) to 111.14(13.13) bpm in group B. in group C it varied from 77.04(9.78) to 83.24(8.36) bpm. Upon statistical comparison in two groups of patient, significant variation was observed throughout the intra-operative period except for the baseline value when no significant variation was observed. (Graph 1)

GRAPH 2: GRAPH SHOWING CHNAGES IN MEAN BLOOD PRESSURE IN BOTH GROUPS.

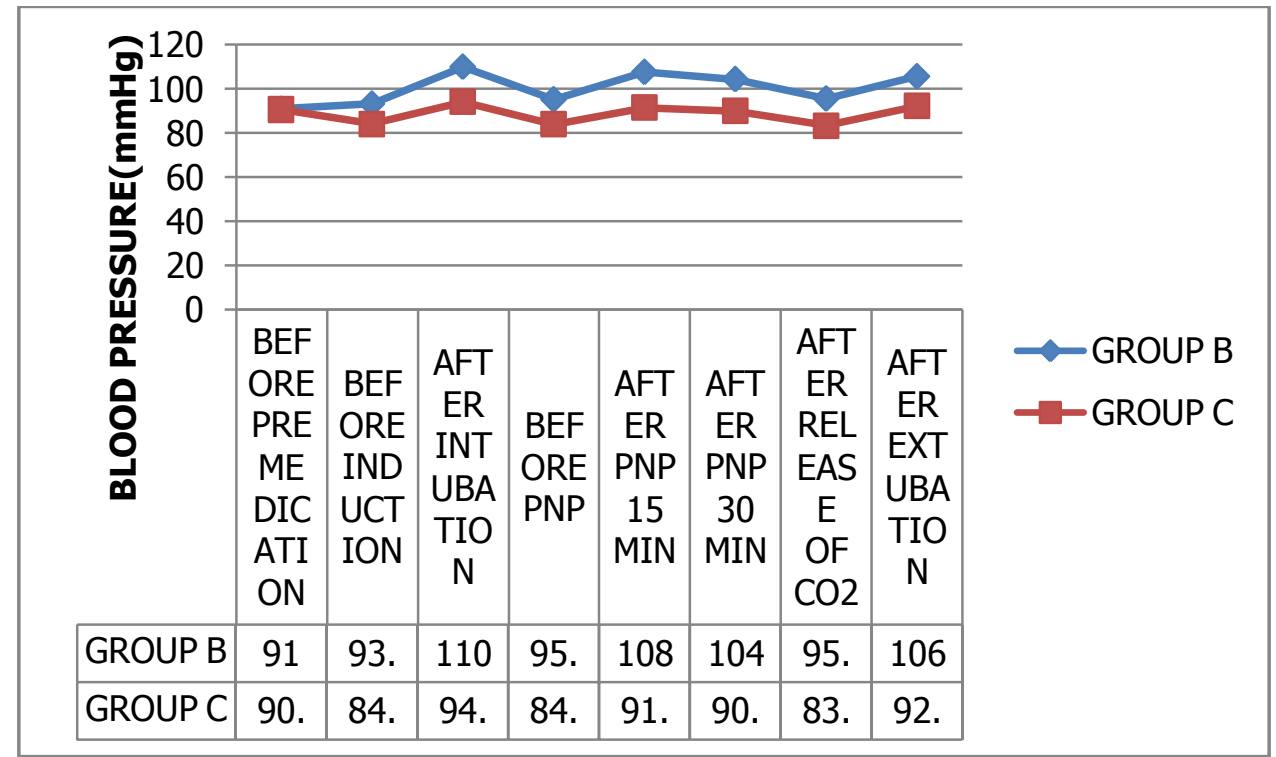

Changes in the blood pressure when compared in the two groups of patients were found to be statistically highly significant except at the base line values where no significant difference was found.

14 out of 50 patients $(28 \%)$ required intra-operative NTG drip for control of hypertension in group B where as no patient required NTG drip in group C. p value was $0.000(\mathrm{p}<0.05)$ and thus the difference was statistically significant.

Postoperatively there were increased number of patients in group $\mathrm{C}$ who were more sedated (OAS score $2 \& 3=20$ ), as compared to group B (OAS score $2 \& 3=8$ ). The average VAS score of patients in group 
B was 6.9(1.52) as compared to 4.4(1.54) in patients of group C when compared on a 10 point scale, showing that intensity of pain was less in group $\mathrm{C}$ as compared to placebo group.

Post operative nausea-vomiting occurred in 19 out of 50 patients (38\%) in group B , where as it occurred in only 6 out of 50(12\%) patients in group C. Post operative shivering occurred in 14 out of 50 patients $(28 \%)$ in group B, where as it occurred in only 3 out of 50 patients $(06 \%)$ in group C. Thos showing that incidence of post operative nausea, vomiting, shivering was less in clonidine group.

\section{DISCUSSION}

Pneumoperitoneum during laparoscopy produces significant hemodynamic changes, which can be detrimental especially in elderly and haemodynamically compromised patients ${ }^{14}$. Various techniques and pharmacological agents have been used to counteract these detrimental effects of pneumoperitoneum.

Ishizaki et $\mathrm{al}^{5}$ tried to evaluate the safe intra-abdominal pressure during laparoscopic surgery. They observed significant fall in cardiac output at $16 \mathrm{~mm} \mathrm{Hg}$ of intra-abdominal pressure. Haemodynamic alterations were not observed at $12 \mathrm{~mm} \mathrm{Hg}$ of intra-abdominal pressure. Based on all these observations the current recommendation is to monitor intra- abdominal pressure and to keep it as low as possible. Cunningham et $\mathrm{al}^{15}$ and Dorsay et $\mathrm{al}^{16}$ assessed the ejection fraction (EF) of left ventricle by trans esophageal echocardiography during pneumoperitoneum. No significant change in ejection fraction was reported up to $15 \mathrm{~mm} \mathrm{Hg}$ of intra-abdominal pressure. Considering all these facts intra abdominal pressure was kept below $14 \mathrm{~mm} \mathrm{Hg}$.

Study by Joris JL et $\mathrm{al}^{17}$ concluded that Vasopressin and catecholamines probably mediate the increase in systemic vascular resistance observed during PNP. Clonidine before PNP reduces catecholamine release and attenuates hemodynamic changes during laparoscopy. In another study it has been concluded that Clonidine inhibits the release of catecholamine and vasopressin and thus modulates the hemodynamic changes induced by pneumoperitoneum ${ }^{13}$.

The alpha2-adrenoceptor agonists have several beneficial actions during the perioperative period. They exert a central sympatholytic action, improving hemodynamic stability in response to endotracheal intubation and surgical stress, reducing the anesthetic and opioid requirements and causing sedation, anxiolysis and analgesia. Furthermore, alpha2-adrenoceptor agonists may offer benefits in the prophylaxis and treatment of perioperative myocardial ischemia. Recent alpha2-adrenoceptor agonists with short duration of action (dexmedetomidine and mivazerol) are adapted for the administration to patients at high risk for coronary artery disease during surgery. The alpha2-adrenoceptor agonists have an analgesic action at several sites of the peripheral and central nervous system. It also causes prolongation of epidurally or intrathecally administered local anesthetics and opioids.

Clonidine, an imidazoline derivative is a selective alpha 2 adrenergic agonist. It is a potent antihypertensive drug. It produces a fall in the heart rate and blood pressure associated with decreased SVR and cardiac output. $150 \mu \mathrm{g}(2.7 \mu \mathrm{g} . \mathrm{kg}$-1) clonidine was administered orally, 90 minutes before surgery in this series. Clonidine (and alha 2 agonists) has been used in various dose ranges through various routes in different studies. Although Joris et $\mathrm{al}^{13}$ used higher dose of clonidine (8micrograms. $\mathrm{Kg}^{-1}$ ), considering the fact that these high dose was seen to be required to decrease vasopressin release in dogs, but still they found that clonidine even at this dose did not decrease the vasopressin release. Malek et $\mathrm{al}^{18}$ used $150 \mu \mathrm{g}$ of clonidine as i.v. infusion and intramuscularly while Sung et $\mathrm{al}^{19}$ and $\mathrm{Yu}$ et $\mathrm{al}^{20}$ used $150 \mu \mathrm{g}$ of oral clonidine as premedication for maintenance of haemodynamic stability during pneumoperitoneum. M.Das et $\mathrm{al}^{21}$ also used $150 \mu \mathrm{g}$ of oral clonidine 90 minutes prior to surgery to prevent hemodynamic response to pneumoperitoneum in laparoscopic cholecystectomy.

In spite of maintaining normocapnia and keeping intra-abdominal pressure below14 $\mathrm{mmHg}$ significant rise in heart rate, systolic blood pressure, diastolic blood pressure and mean arterial pressure was noticed in Group B. Rise in systolic, diastolic and mean arterial pressure was more than $20 \%$ from the baseline. Slight fall in systolic blood pressure, diastolic blood pressure and mean arterial pressure was noticed following premedication with clonidine. Following intubation and pneumoperitoneum, increase in arterial pressure was noticed but it never crossed the base line value. Hence clonidine premedication was able to achieve hemodynamic stability during pneumoperitoneum. Similar findings were reported by, Joris et al 3, Malek et al ${ }^{18}$ , Sung et $\mathrm{al}^{19}$, Yu et $\mathrm{al}^{20}$ and $\mathrm{M}$ Das et $\mathrm{al}^{21}$.

Nitroglycerine drip was not required in any patients in group c where as $28 \%$ of patients in placebo group required its use for control of intraoperative hypertension.

Laryngoscopy and endotracheal intubation, pneumoperitoneum, extubation are all associated with sympathetic stimulation in body. Clonidine being a central sympatholytic was expected to blunt hemodynamic responses to these stimuli, and our findings also confirmed the same. Clonidine has been shown to blunt pressor response to laryngoscopy and endotracheal intubation in various studies using various doses ${ }^{22}$.

In our study design, had isoflurane dose been used to keep hemodynamic stable during laparoscopy, isoflurane requirements would have definitely gone up in group B and would have decreased in patients in group C. 
Similar finding was observed in study by Sung CS et $\mathrm{al}^{19}$, who found that isoflurane requirements were less by $30 \%$ in patients who had received clonidine premedication.

Although one patient developed bradycardia in clonidine group, he responded well to single dose of atropine of $0.6 \mathrm{mg}$. Clonidine related bradycardia has rarely been described as a side effect at commonly prescribed doses, rather is more commonly associated with clonidine poisoning/overdose ${ }^{23}$. Patients more susceptible to the development of bradycardia during treatment with clonidine may have one of the following identified risk factors: patients with renal insufficiency, patients with clinical sinus node dysfunction, and patient already receiving another sympatholytic agent. Even the presentation and treatment varies, from asymptomatic to symptomatic patients and treatment varying from simple discontinuation of drug (when taking treatment as antihypertensive), to receiving inj. Atropine, or inj. Isoprenaline or even temporary pacing may be required ${ }^{24}$.

The adverse effects in the postoperative period were less in the patients who had clonidine premedication in comparison with placebo premedication.

In immediate post-operative period clonidine has also been shown to cause increased sedation, though the patients were arousable. The data was comparable to that of study by M.Das et $\mathrm{al}^{21}$. Intensity of pain was less in group $\mathrm{C}$ as compared to group $\mathrm{B}$ during the early postoperative period.

There was decreased incidence of post operative nausea, vomiting, shivering in patients who received clonidine premedication. Clonidine increases gastrointestinal motility by decreasing sympathetic outflow and increasing parasympathetic outflow from the central nervous system. Clonidine inhibits cold thermoregulatory response due to an effect on central integration control and output from the thermoregulatory centers ${ }^{25}$. Thus authors also opined that clonidine can be used as an effective agent for inhibition of perioperative shivering which can adversely increase metabolic rate and cardiac work and may also disrupt surgical repair or result in wound dehiscence.

To conclude, an attempt has been made in the present study to assess the effects of pneumoperitoneum on hemodynamic and the effect of clonidine premedication to prevent same. The conclusions drawn from the study are:

- Pneumoperitoneum used during laparoscopic cholecystectomy causes sympathetic activation leading to alteration in hemodynamics.

- Premedication with 150 micrograms of oral clonidine in ASA I and II patients has been found to be relatively safe and effective method to provide stable hemodynamics intraoperatively and as protection against stress response triggered by pneumoperitoneum in patients undergoing laparoscopic cholecystectomy.

- Oral clonidine premedication also offers additional advantage of reduction of postoperative complications such as pain, nausea-vomiting, and shivering.

- Hence 150 micrograms of oral clonidine can reasonably be recommended as premedication for all laparoscopic cholecystectomies and other laparoscopic surgeries in otherwise healthy patients.

However further studies are necessary to find out its efficacy in elderly and ASA III and IV patients, particularly in compromised cardiovascular function.

\section{BIBILIOGRAPHY}

[1]. $\quad$ NIH Consensus conference. Gall stones and laparoscopic cholecystectomy. JAMA 1993;269:1018-24.

[2]. Osborne DA, Alexander G, Boe B, Zervos EE. Laparoscopic cholecystectomy: past, present and future. Surg Technol Int 2006;15:81-5.

[3]. Menes T, Spivak H. Laparoscopy: searching for the proper insufflation gas. Surg Endosc 2000;14(11):1050-6.

[4]. Dexter S.P.L. , Vucevic M. , Gibson J. , McMahon M. J. Hemodynamic consequences of high- and low-pressure capnoperitoneum during laparoscopic cholecystectomy Surg Endosc 1999;13(4):376-81.

[5]. Ishizaki Y, Bandae Y, Shimomura K, Abe H, Ohtomo Y, Idezuki Y. Safe intra-abdominal pressure of carbondioxide pneumoperitoneum during laparoscopic surgery. Surgery 1993;114(3):549-54.

[6]. Gurusamy KS, Samraj K, Davidson BR. Abdominal lift for laparoscopic cholecystectomy. Cochrane database Syst Rev 2008;16(2):CD006574.

[7]. van Zundert AA, Stultiens G, Jakimowicz JJ, Peek D, van der Ham WG, Korsten HH, Wildsmith JA. Laparoscopic cholecystectomy under segmental thoracic spinal anesthesia : a feasibility study Br J Anaesth 2007;98(5):682-6.

[8]. Youssef MA, saleh Al-Mulhim A. Effects of different anesthetic techniques on antidiuretic harmone secretion during laparoscopic cholecystectomy. Surg Endosc 2007;21(9):1543-8.

[9]. Feig BW, berger Dh, Doughtery TB, et al. Pharmacological interventions can re establish baseline hemodynamic parameters during laparoscopy. Surgery 1994; $116: 733-7$.

[10]. A.-M. Koivusalo, M. Scheinin, I. Tikkanen, T. Yli-Suomu, S. Ristkari, J. Laakso, L. Lindgren. Effects of esmolol on hemodynamic responses to CO2 pneumoperitoneum for laparoscopic surgery. Acta Anaesthesiol Scand 2008:510-7.

[11]. Jee .D, Lee .D, Yun .S, Lee C. magnesium sulphate attenuates arterial pressure increses during laparoscopic cholecystectomy. Br J Anaesth 2009;103(4):484-89.

[12]. Aho M, Scheinin M, Lehtinen AM, Erkola O, Vuorinen J, Korttila K. Intramuscularly administered dexmedetomidine attenuates hemodynamic and stress hormone responses to gynecologic laparoscopy. Anesth Analg 1992;75:932-9.

[13]. Joris J, Chiche JD, Lamy M. Clonidine reduced hemodynamic changes induced by pneumoperitoneum during laparoscopic cholecystectomy. Br j Anaesth 1995; 74 (suppl) : A124. 
[14]. Dhoste K, Lacoste L, Karayan J, et al. Haemodynamic and ventilator changes during laparoscopic cholecystectomy in elderly ASA III patients. Can J Anaesth 1996; $43: 783-8$.

[15]. Cunningham AJ,Turner J, Rosenbaum S, Rafferty T.Transesophageal echocardiographic assessment of hemodynamic function during laparoscopic cholecystectomy. Br J Anaesth 1993;70(6):621-5.

[16]. Dorsay GA, Greene FL, Baysinger CL. Hemodynamic changes during laparoscopic cholecystectomy monitores with trans esophageal echocardiography. Surg Endosc 1995; 9: 128 .

[17]. Jean L Joris, Jean-Daniel Chiche, Jean-Luc M. Canivet, Nicolas J. jacquet, jean Jacques Y. Legros, maurice L. Lamy. Hemodynamic changes induced by laparoscopy and their endocrine correlates: effects of clonidine. JACC 1998;32(5):138996.

[18]. Malek J, Knor J, Kurzova A, Lopourova M. Adverse hemodynamic changes during laparoscopic cholecystectomy and their possible suppression with clonidine premedication. Comparison with intravenous and intramuscular premedication. Rozhl Chir 1999;78(6):286-91.

[19]. Sung CS, Lin SH, Chan KH, Chang WK, Chow LH, Lee TY. Effect of oral clonidine premedication on perioperative hemodynamic response and postoperative analgesic requirement for patients undergoing laparoscopic cholecystectomy. Acta Anaesthesiol Sin 2000;38(1):23-9.

[20]. Yu HP, Hseu SS, Yien HW, Teng YH, Chan KH. Oral clonidine premedication preserves heart rate variability for patients undergoing larparoscopic cholecystectomy. Acta Anaesthesiol Scand 2003;47(2):185-90.

[21]. Mrinmoy Das, Manjushree Ray, Gauri Mukherjee. Hemodynamic changes during laparoscopic cholecystectomy: effect of oral clonidine premedication. Indian J Anaesth 2007;51(3):205-10.

[22]. Laurito CE, Baughman VL, Becker GL, DeSilva TW, Carranza CJ. The effectiveness of oral clonidine as a sedative/anxiolytic and as a drug to blunt the hemodynamic responses to laryngoscopy. J Clin Anesth 1991;3(3):186-93.

[23]. Golusinski LL jr, Blount BW. Clonidine induced bradycardia. J Fam Pract 1995;41(4):399-401.

[24]. Benjamin F. Byrd III, H. Wade Collins, R. Kirby primm. Risk factors for severe bradycardia during oral clonidine therapy Arch Intern Med 10988;148(3):729-33

[25]. George Nicolaou, A. Andrew Chen, Chad E. Johnston, Glen P. Kenny, Gerald K. Bristow, Gordon G. Giesbrecht. Clonidine decreases vaso-constriction and shivering tresholds, without affecting the sweating treshold Can J Anaesth 1997;44(6):636-42 